\title{
Glasgow Coma Scale-NINDS Version Clinical Classification
}

National Cancer Institute

\section{Source}

National Cancer Institute. Glasgow Coma Scale-NINDS Version Clinical Classification. NCI

Thesaurus. Code C124710.

A standardized rating scale developed by Teasdale and Jennett in 1974, which is a classification system used to assess the level of consciousness. The NINDS version measures eye opening, motor and verbal responses. 